\title{
Respons Awal Obat Antiepilepsi Monoterapi pada Pasien Epilepsi Baru
}

\author{
Nurcahaya Sinaga, ${ }^{1}$ Dwi Putro Widodo, ${ }^{2}$ Setyo Handryastuti ${ }^{2}$ \\ ${ }^{1}$ Program Studi Spesialis Ilmu Kesehatan Anak, ${ }^{2}$ Departemen Ilmu Kesehatan Anak Fakultas Kedokteran Universitas Indonesia
}

Latar belakang. Epilepsi merupakan satu dari penyakit neurologi yang sering menyebabkan disabilitas dan kematian. Prediktor terbaik dalam menentukan remisi epilepsi adalah respons awal terhadap OAE. Terdapat beberapa faktor yang memengaruhi respons awal terapi diantaranya etiologi epilepsi, jumlah kejang sebelum pengobatan, bentuk bangkitan kejang, status neurologi, usia awitan dan gambaran elektroensefalografi.

Tujuan. Mengetahui faktor-faktor yang memengaruhi respons awal OAE pada pasien epilepsi baru pertama kali.

Metode. Penelitian merupakan penelitian kohort prospektif dengan melihat respons awal OAE pada anak penderita epilepsi baru selama 3 bulan yang berobat ke poliklinik rawat jalan RSUP dr Cipto Mangunkusumo sejak Januari 2017 sampai Agustus 2017. Faktor-faktor risiko dianalisis secara bivariat dan multivariat.

Hasil. Insiden epilepsi baru adalah 21,9\%. Karakteristik pasien epilepsi baru yang mendapat OAE monoterapi sebagian besar berumur $\geq 1$ tahun. Etiologi struktural, awitan kejang $\geq 1$ tahun, jumlah kejang sebelum pengobatan $\geq 10$ ditemukan lebih banyak. Pasien epilepsi tanpa kelainan neurologi ditemukan lebih sedikit dibanding dengan kelainan neurologi. Sebagian besar pasien adalah dengan bangkitan kejang umum dan dengan gambaran kelainan EEG. Respons awal yang baik pada pasien epilepsi baru terhadap OAE monoterapi adalah $77,2 \%$ dalam 3 bulan pengobatan. Faktor yang berhubungan dengan respon awal baik adalah etiologi epilepsi, jumlah kejang, kelainan neurologi, bangkitan kejang, dan gambaran EEG. Sementara faktor risiko respons awal dalam 3 bulan pemberian OAE monoterapi adalah jumlah kejang dan gambaran EEG.

Kesimpulan. Faktor yang berperan terhadap respons awal terapi OAE monoterapi adalah jumlah kejang dan gambaran EEG. Sari Pediatri 2021;22(5): 270-6

Kata kunci : epilepsi, faktor risiko, respons awal OAE monoterapi

\section{Early Response to Monotherapy Antiepileptic Drugs in Patients with Newly Diagnosed Epilepsy}

Nurcahaya Sinaga, ${ }^{1}$ Dwi Putro Widodo, ${ }^{2}$ Setyo Handryastuti ${ }^{2}$

Background. Epilepsy is one of neurology disorder than can cause disability event death. Early predictor to define remission of epilepsy is the early response to monotherapy antiepileptic drugs. There are several factors the influence the early response of antiepileptic drugs, such as etiology of epilepsy, a number of seizure before treatment, type of seizures, neurology deficits, age of onset and electroensefalography findings.

Objective. To determine the factors that influence the early response to monotherapy antiepileptic drugs for the newly diagnosed epilepsy patient.

Method. Cohort prospective study was conducted 92 newly diagnosed epilepsy patients. The response to monotherapy antiepileptic drugs was observed for the first three months of treatment.

Result. The incidence of newly diagnosed epilepsy was $21,9 \%$ in this study. Patients with structural etiology, onset of seizure $\geq 1$ year, number of seizure before treatment 10 and with neurology deficits were more than others. Overall, 82,6\% of patients with generalized seizure and 57,6\% with normal EEG findings. Early response to monotherapy antiepileptic drugs was 77,2\% in the first three month of treatment. The factors that influence the early response to monotherapy antiepileptic drugs were etiology of epilepsy, number of seizure, type of seizures, neurology deficits, and EEG findings. Risk factor to early response were number of seizure and EEG findings. Conclusion. A greater number of seizure before diagnosis and EEG findings are risk factor early response monotherapy antiepileptic drug. Sari Pediatri 2021;22(5):270-6

Keywords : epilepsy, risk factor, early response to monotherapy antiepileptic drugs

Alamat korespondensi: Nurcahaya Sinaga. RSU Haji Medan Pemprov Sumatra Utara. Email: Sinaganurcahaya33@yahoo.co.id 
I dentifikasi sejak awal terhadap pasien epilepsi yang berisiko untuk menjadi epilepsi intraktabel harus segera dilakukan. Respons terhadap obat anti epilepsi (OAE) sejak awal merupakan faktor prognostik yang kuat. Pasien epilepsi yang tidak respons di awal pengobatan hanya 11\% yang akan mengalami bebas kejang. Pasien yang tidak respon dengan OAE pertama, 14\% menjadi bebas kejang ketika diobati dengan OAE kedua, tetapi hanya 3\% yang bebas kejang dengan kombinasi dua OAE. Hal ini menyebabkan epilepsi yang refrakter dapat diprediksi sejak awal jika tidak respons terhadap terapi OAE. ${ }^{1}$

Penilaian respons awal terhadap OAE pada pasien baru diperlukan agar dokter dapat segera melakukan rujukan ketika pasien menunjukkan respons tidak baik. Selain itu dapat dilakukan evaluasi dan monitor yang lebih ketat untuk mencegah kejang menjadi intraktabel. Penelitian ini juga mempunyai arti klinis yang penting dalam memprediksi epilepsi yang resistan terhadap OAE pada pasien epilepsi yang baru terdiagnosis. Selain itu dapat dilakukan identifikasi terhadap pasien epilepsi yang sejak awal tidak respons dengan OAE monoterapi sehingga dapat dirujuk untuk tindakan selanjutnya, seperti politerapi atau bahkan operasi.

Penelitian ini dilakukan untuk mengetahui faktorfaktor yang memengaruhi respons awal terapi OAE monoterapi pada pasien epilepsi baru pertama kali di RSCM, karakteristik pasien epilepsi baru yang mendapat monoterapi OAE berdasarkan etiologi, jumlah kejang, jenis bangkitan kejang, usia awitan, status neurologi dan pemeriksaan elektroensefalografi (EEG), dan bagaimana respons awal monoterapi OAE.

\section{Metode}

Penelitian dilakukan dengan desain kohort prospektif untuk melihat respons awal terapi pada pasien epilepsi baru selama 3 bulan. Dilakukan di Poliklinik Neurologi Anak IKA FKUI-RSCM dalam kurun waktu Januari sampai dengan Agustus 2017. Populasi penelitian adalah semua anak yang baru terdiagnosis epilepsi dengan usia di bawah 17 tahun. Populasi terjangkau adalah anak yang memenuhi kriteria di atas yang berobat ke Poliklinik Neurologi Anak IKA FKUI-RSCM.

Kriteria inklusi adalah pasien epilepsi baru dan didiagnosis di RSCM, pasien epilepsi baru rujukan dari luar RSCM yang didiagnosis epilepsi, pasien lama yang baru terdiagnosis kurang dari 3 bulan, seluruh pasien berumur dibawah 17 tahun dan konfirmasi diagnosis oleh konsultan neurologi anak dan orangtua bersedia anaknya menjadi subyek penelitian. Kriteria eksklusi adalah yang telah mendapat lebih dari satu OAE, tidak patuh minum obat, adanya kelainan metabolik bawaan dan sindroma epilepsi.

Dilakukan pencatatan data dasar berupa identitas, umur dan jenis kelainan pada formulir penelitian. Anamnesis untuk diagnosis epilepsi dilakukan dengan menanyakan umur, karakteristik serangan, deskripsi kejang, riwayat kehamilan dan persalinan, berat badan lahir, riwayat kejang sebelumnya, riwayat perkembangan. Pemeriksaan fisis lengkap dilakukan pada semua pasien termasuk berat badan, lingkaran kepala, kelainan kongenital, dan status neurologis. Diagnosis klinis epilepsi awal dilakukan dan kemudian pasien diberikan pengobatan berdasarkan protokol pengobatan epilepsi. Dilakukan pemeriksaan EEG rutin pada seluruh pasien, sedangkan MRI kepala terutama ditujukan pada pasien dengan satu atau lebih hal seperti berikut : kejang fokal baik secara anamnesis atau EEG, kejang umum berumur di bawah 1 tahun, kelainan neurologi fokal secara klinis dan dicurigai kemungkinan adanya lesi serebral.

Tatalaksana dilakukan berdasarkan jenis epilepsi dan pemberian OAE monoterapi melalui pemilihan jenis obat berdasarkan protokol pengobatan epilepsi. Dilakukan kontrol 2 minggu pertama setelah dilakukan diagnosis dan pengobatan, kemudian kontrol tiap bulannya dengan penilaian respons dini/awal 3 bulan pengobatan. Pada saat kontrol dievaluasi respons terhadap pengobatan yaitu bebas kejang, jika masih kejang dievaluasi dosis obat dan bagaimana kepatuhan minum OAE. Evaluasi bebas kejang pertama dilakukan 2 minggu setelah pemberian obat dengan catatan jika kejang masih ada dapat segera kontrol untuk penyesuaian dosis obat. Kemudian kontrol berikutnya adalah tiap bulan sampai 3 bulan bebas kejang, saat kejang benar- benar tidak dijumpai sama sekali. Pasien lama yang baru terdiagnosis epilepsi kurang dari 3 bulan di RSCM pencatatan data diambil dari catatan rekam medik. Semua data pemeriksaan dicatat dalam formulir penelitian.

Penelitian ini mendapat persetujuan etik dari Komisi Etik Fakultas Kedokteran Indonesia dengan surat keterangan lolos etik nomor 422/UN2.F1/ ETIK/2017. 


\section{Hasil}

Selama kurun waktu penelitian selama 8 bulan didapatkan 97 anak epilepsi baru dengan usia awitan di 4 bulan sampai dengan 17 tahun yang berkunjung ke RSUPN dr Cipto Mangunkusumo. Jumlah seluruh pasien baru yang datang ke poli neurologi anak sebanyak 442 orang anak sehingga insiden kasus epilepsi baru sebesar 21,9\%. Lima pasien tidak diikut sertakan karena kepatuhan minum obat yang buruk dan tidak bisa dihubungi untuk mengetahui respons terhadap OAE. Dengan demikian terdapat 92 pasien yang memenuhi persyaratan penelitian.

Tabel 2 menunjukkan etiologi epilepsi, jumlah kejang, ada tidaknya gangguan neurologi, bangkitan kejang dan gambaran EEG merupakan faktor yang memengaruhi respons awal terhadap obat antiepilepsi monoterapi pada pasien epilepsi baru.

Tabel di atas menunjukkan jumlah kejang dan gambaran elektroensefalografi merupakan faktor risiko terhadap respons awal obat antiepilepsi monoterapi pada pasien epilepsi baru.

\section{Pembahasan}

Pasien anak dengan epilepsi yang ikut dalam penelitian ini merupakan kasus baru yang datang ke poliklinik Rumah Sakit Cipto Mangunkusumo (RSCM), Jakarta. Kasus baru merupakan kasus yang didiagnosis di

\begin{tabular}{|c|c|c|}
\hline Variabel & Jumlah & Persentase \\
\hline \multicolumn{3}{|l|}{ Jenis kelamin } \\
\hline Laki laki & 50 & 54,3 \\
\hline Perempuan & 42 & 45,7 \\
\hline \multicolumn{3}{|l|}{ Usia (tahun) } \\
\hline$<1$ & 18 & 19,6 \\
\hline$\geq 1$ & 74 & 80,4 \\
\hline \multicolumn{3}{|l|}{ Etiologi } \\
\hline Genetik & 44 & 47,8 \\
\hline Struktural & 48 & 52,2 \\
\hline \multicolumn{3}{|l|}{ Awitan kejang (tahun) } \\
\hline$<1$ & 54 & 58,7 \\
\hline \multicolumn{3}{|l|}{ Jumlah kejang } \\
\hline$<10$ & 37 & 40,2 \\
\hline$\geq 10$ & 55 & 59,8 \\
\hline \multicolumn{3}{|l|}{ Status neurologi } \\
\hline Ditemukan kelainan & $\begin{array}{l}36 \\
36\end{array}$ & 60,9 \\
\hline Tidak ditemukan kelainan & & 39,1 \\
\hline \multicolumn{3}{|l|}{ Bangkitan kejang } \\
\hline Fokal, umum & 16 & 17,4 \\
\hline Umum & 76 & 82,6 \\
\hline \multicolumn{3}{|l|}{ EEG } \\
\hline Abnormal & 39 & 42,4 \\
\hline Normal & 53 & 57,6 \\
\hline \multicolumn{3}{|l|}{ Respons 3 bulan } \\
\hline Baik & 71 & 77,2 \\
\hline Buruk & 21 & 22,8 \\
\hline
\end{tabular}


Nurcahaya Sinaga dkk: Respons awal obat antiepilepsi monoterapi pada pasien epilepsi baru

Tabel 2. Faktor-faktor yang berpengaruh terhadap respons awal yang baik pada monoterapi OAE

\begin{tabular}{|c|c|c|c|c|c|}
\hline & Respon & 3 bulan & \multirow[t]{2}{*}{ Nilai $p^{*}$} & \multirow[t]{2}{*}{ aRR } & \multirow[t]{2}{*}{ IK95\% } \\
\hline & Baik & Buruk & & & \\
\hline \multicolumn{6}{|l|}{ Jenis kelamin } \\
\hline Laki-laki & 38 & 12 & 0,77 & 0,9 & $0.4-2,2$ \\
\hline Perempuan & 33 & 9 & & & \\
\hline \multicolumn{6}{|l|}{ Usia (tahun) } \\
\hline$<1$ & 14 & 4 & 0,946 & 1,0 & $0,3-3,1$ \\
\hline$\geq 1$ & 57 & 17 & & & \\
\hline \multicolumn{6}{|l|}{ Etiologi } \\
\hline Genetik & 41 & 3 & $<0,001^{*}$ & 8,2 & $1,6-18,7$ \\
\hline Struktural & 30 & 18 & & & \\
\hline \multicolumn{6}{|l|}{ Awitan kejang (tahun) } \\
\hline$<1$ & 29 & 9 & 0,869 & 0,9 & $0.4-2,2$ \\
\hline$\geq 1$ & 42 & 12 & & & \\
\hline \multicolumn{6}{|l|}{ Jumlah kejang } \\
\hline$<10$ & 35 & 2 & $0,001^{*}$ & 9,2 & $6,4-27,4$ \\
\hline$\geq 10$ & 36 & 19 & & & \\
\hline \multicolumn{6}{|l|}{ Status neurologi } \\
\hline Tidak ditemukan kelainan & 33 & 3 & $0,008^{*}$ & 5,2 & $1,1-13,1$ \\
\hline Ditemukan kelainan & 38 & 18 & & & \\
\hline \multicolumn{6}{|l|}{ Bangkitan kejang } \\
\hline Umum & 63 & 13 & $0,008^{*}$ & 4,8 & $1,2-7,0$ \\
\hline Umum, fokal & 8 & 8 & & & \\
\hline \multicolumn{6}{|l|}{ EEG } \\
\hline Normal & 48 & 5 & $0,002^{*}$ & 6,7 & $4,3-11,9$ \\
\hline Abnormal & 23 & 16 & & & \\
\hline
\end{tabular}

Tabel 3. Faktor risiko respons awal OAE monoterapi pada pasien epilepsi baru

\begin{tabular}{lccccc}
\hline Variabel & $\mathrm{B}$ & $\mathrm{SE}$ & $\mathrm{P}$ & aRR & IK 95\% \\
\hline Jumlah kejang & 1,54 & 0,75 & 0,040 & 4,7 & $1,1-20,6$ \\
EEG & 1,18 & 0,52 & 0,023 & 3,3 & $1,2-9,0$ \\
\hline
\end{tabular}

RSCM dan sejak awal mendapatkan pengobatan OAE monoterapi atau kasus rujukan dari RS luar untuk pemeriksaan EEG sehingga OAE sudah diberikan di tempat asal pengirim. Tatalaksana pasien dilakukan dengan mengikuti anjuran pengobatan sesuai dengan protokol yang ada pada penelitian. Penelitian prospektif berbasis rumah sakit sebelumnya juga melibatkan subyek yang sebagian besar merupakan pasien rujukan. ${ }^{2-5}$

Batasan operasional dalam menentukan etiologi sebenarnya lebih kepada klinis karena tidak semua pasien dilakukan pemeriksaan pencitraan, seperti MRI, functional MRI ( $f M R I)$, magnetic resonance spectroscopy (MRS) sehingga kelainan struktural sebagai etiologi belum sepenuhnya dapat ditentukan. Pemeriksaan analisis genetik sebagai etiologi epilepsi tidak dilakukan karena keterbatasan fasilitas.

Batasan epilepsi yang digunakan adalah batasan The International League Against Epilepsy (ILAE) tahun 2017, terdapat tiga hal yang dilihat untuk menentukan diagnosis epilepsi, yaitu pertama tipe kejang, kedua tipe epilepsi, dan ketiga adalah menentukan apakah diagnosis termasuk sindrom epilepsi. ${ }^{6}$ 
Kami mendapatkan 77,2\% menunjukkan respons awal yang baik dalam 3 bulan pertama pengobatan dengan OAE monoterapi. Kepustakaan menyebutkan bahwa $70 \%$ epilepsi idiopatik mempunyai respons yang cepat, 76\% akan bebas kejang dalam 12 bulan, sisanya akan mengalami bebas kejang dan relaps yang berfluktuasi. ${ }^{7}$ Kwan dan Brodie ${ }^{8}$ menemukan hampir $50 \%$ anak epilepsi tetap kejang dengan OAE lini pertama setelah 1 tahun pengobatan.

Sebaran jenis kelamin dari 92 subyek, yaitu 54,3\% laki-laki dan 45,7\% perempuan. Secara umum, angka kejadian epilepsi lebih tinggi pada laki-laki meskipun hasil ini tidak selalu konsisten, tergantung perbedaan geografis dan usia. Beberapa faktor diduga berpengaruh, antara lain, pada masa bayi terdapat faktor rentan yang diturunkan secara X-linked, serta lebih rentannya bayi laki-laki terhadap infeksi dan asfiksia. Sementara pada masa dewasa, laki-laki diperkirakan lebih banyak terpajan terhadap aktivitas yang berisiko menyebabkan cedera kepala. Selain itu, kemungkinan terdapat kasus anak perempuan dengan epilepsi yang disembunyikan, terutama di negara berkembang sehingga tidak tercatat karena tidak dibawa berobat.'

Usia awitan pada penelitian terbagi menjadi usia $<1$ tahun dan $\geq 1$ tahun. Tidak terdapat perbedaan proporsi jenis kelamin antara kelompok respons awal baik dengan yang buruk. Park $\mathrm{dkk}^{10}$ menemukan usia awitan kejang merupakan faktor yang memengaruhi respons terhadap OAE pada pasien epilepsi baru. Casseta $\mathrm{dkk}^{11}$ menemukan usia awitan $<1$ tahun merupakan faktor prognostik epilepsi intraktabel.

Etiologi epilepsi merupakan struktural lebih banyak dibandingkan etiologi genetik. Penelitian Wirrell $\mathrm{dkk}^{12}$ menemukan epilepsi dengan etiologi struktural metabolik lebih banyak dari total subyek yang etiologinya dapat diidentifikasi, selebihnya merupakan etiologi genetik dan tidak diketahui. Untuk kelompok usia lebih muda, penelitian di RSCM Jakarta tahun 2012 mendapatkan sebagian besar merupakan epilepsi simtomatik-kriptogenik untuk anak usia $<5$ tahun. ${ }^{13}$

Lima belas persen subyek telah mengalami kejang selama satu tahun sebelum berobat. Angka penundaan pengobatan ini masih tinggi dan dapat disebabkan beberapa alasan, antara lain, kesulitan akses fasilitas pengobatan, ketidaktahuan orang tua dan masih kuatnya stigma yang melekat pada epilepsi. ${ }^{14,15}$ Dragoumi dkk ${ }^{7}$ pada penelitian tahun 2013 di Yunani mendapatkan 10,9\% anak dengan epilepsi baru berobat setelah satu tahun awitan. Berg $\mathrm{dkk}^{16}$ pada 1999 menemukan 20\% kasus epilepsi anak tidak diobati pada saat diagnosis inisial, $10 \%$ berlanjut tidak diobati sampai 1 tahun. Sebagian besar jumlah kejang $>10$ kali sebelum terapi diberikan.

Kejang umum ditemukan pada sebagian besar subyek diikuti kejang fokal dan fokal sekunder umum. Hasil ini berbeda dengan Camfield dkk ${ }^{17}$ yang menemukan kejang umum tonik klonik dibanding kejang fokal tidak jauh berbeda jumlahnya. Namun, perbedaan ini mungkin terjadi karena sejak awal terdapat perbedaan dalam rekruitmen subyek. Subyek dengan kejang absans dieksklusi, subyek yang lebih banyak dan pembagian yang lebih luas.

Hasil penelitian kami menunjukkan 5,4\% subyek memiliki lebih dari satu jenis kejang yang kemudian menunjukkan respon awal yang buruk terhadap OAE monoterapi. Zhang $\mathrm{dkk}^{18}$ menemukan bahwa anak dengan epilepsi yang baru terdiagnosis dan memiliki lebih dari satu tipe kejang, berisiko lebih tinggi untuk tidak respons terhadap OAE. Abnormalitas EEG penelitian kami mencapai 42,4\%. Penelitian Zhang $\mathrm{dkk}^{18}$ mendapatkan jumlah yang lebih tinggi yang disebabkan pemeriksaan EEG dilakukan dengan monitor 24 jam pada subyek penelitiannya.

Respons awal yang baik menunjukkan hubungan yang bermakna dengan etiologi genetik. Respons awal terhadap terapi berbeda dengan remisi kejang secara keseluruhan. Respons awal baik terhadap OAE tidak menjamin akan tetap bebas kejang seterusnya. Terdapat $10,4 \%$ pasien epilepsi mengalami kejang berulang kembali setelah respons awal yang baik dan $5 \%$ berlanjut menjadi epilepsi intraktabel. Sebaliknya, epilepsi yang tidak respons atau respons buruk diawal pengobatan tidak selalu menunjukkan prognosis yang buruk. ${ }^{19}$

Mac Donald $\mathrm{dkk}^{20}$ menemukan respons awal yang baik terhadap pengobatan epilepsi tidak memengaruhi keberhasilan terapi atau remisi jangka panjang. Tipe kejang maupun etiologi tidak merupakan variabel yang berhubungan dengan respons di awal pengobatan. Faktor dominan yang justru memengaruhi adalah jumlah kejang dalam 6 bulan sebelum pengobatan diberikan. Penelitian ini menentukan etiologi berdasarkan klinis sehingga etiologi genetik sebagai faktor yang berhubungan dengan respons awal yang baik tidak serta merta dapat diterapkan secara luas.

Jumlah kejang $<10$ kali berpengaruh secara bermakna terhadap respons awal terapi. Pasien dengan 
jumlah kejang sebelum pengobatan $<10$ menunjukkan respons awal terapi yang baik dibanding jumlah kejang $\geq 10$. Mohanraj \& Brodie $^{19}$ menemukan hubungan bermakna antara jumlah kejang yang rendah sebelum pengobatan dengan respons yang baik terhadap OAE. Jumlah kejang dalam 3 bulan pertama setelah diagnosis dan mulai pengobatan dapat memprediksi respons awal terapi. Pasien epilepsi yang bebas kejang dalam 3 bulan pengobatan akan menjadi remisi setelah 2 tahun. Sepertiga kasus akan mengalami resistan terhadap OAE dan selanjutnya akan menjadi epilepsi yang refrakter terhadap OAE. Dengan demikian, respons terhadap OAE pertama merupakan prediktor terhadap prognosis. Abimbola $\mathrm{dkk}^{21}$ menemukan jumlah kejang dalam 6 bulan pengobatan OAE dapat menentukan strategi pengobatan selanjutnya. Sillanpaa dan Schmidt ${ }^{22}$ menemukan selain jumlah kejang sebelum pengobatan, frekuensi kejang selama pengobatan merupakan faktor prognostik bebas kejang dalam memprediksi respons jangka panjang pada anak epilepsi.

Casetta $\mathrm{dkk}^{11}$ menemukan proporsi resistensi obat lebih tinggi pada subyek dengan kejang sebelum pengobatan sebanyak lebih atau sama dengan 10 kali, meskipun tidak ditemukan kemaknaan secara statistik. Ramzi $\mathrm{dkk}^{23}$ menemukan bahwa jumlah kejang sebelum pengobatan sebanyak 20 atau lebih merupakan faktor risiko epilepsi intraktabel- Pasien epilepsi yang memiliki jumlah kejang sebelum pengobatan lebih banyak sebelum pengobatan 10 kali atau lebih memiliki kemungkinan lebih kecil untuk dapat menghentikan pengobatan. Bahkan, frekuensi kejang sebelum terapi $>10$ kali dapat memprediksi kegagalan terapi dengan obat pertama. Hal ini disebabkan pajanan terhadap kejang yang tidak terkendali dapat menyebabkan kerusakan otak dan memperluas fokus epileptogenesis. ${ }^{17}$

Respons awal yang baik dalam 3 bulan terapi OAE lebih banyak pada pasien dengan status neurologi yang normal. Pasien epilepsi baru dengan kelainan neurologis 4 kali lebih banyak tidak berespons terhadap OAE monoterapi. Namun, kelainan neurologis tidak selalu berakibat buruk terhadap remisi atau gagal dalam pengobatan. Kelainan neurologis juga tidak merupakan faktor prognostik terhadap luaran setelah 2 tahun pengobatan dan tidak merupakan faktor risiko prediksi luaran prognostik. ${ }^{12}$

Kejang umum berhubungan dengan respons awal yang baik terhadap terapi dibandingkan kejang fokal. Pasien epilepsi dengan kejang tonik klonik dan absans kemungkinan akan mencapai remisi lebih baik dibandingkan kejang parsial kompleks sebesar. Anak dengan usia awitan di bawah 36 bulan dengan epilepsi fokal kemungkinan lebih besar untuk menjadi intraktabel. Tipe kejang yang multipel dan perubahan tipe kejang selama pengobatan merupakan faktor prognostik yang buruk terhadap respons terapi. ${ }^{12}$

Gambaran EEG normal menunjukkan proporsi lebih tinggi pada kelompok dengan respon awal baik terhadap OAE monoterapi. Pemeriksaan EEG yang dilakukan segera setelah kejang lebih memungkinkan untuk mendeteksi sejumlah abnormalitas dan lebih besar mempunyai nilai prognostik. Kelainan EEG setelah enam bulan pengobatan secara bermakna berhubungan dengan resistensi obat dan pengaruhnya lebih kuat dibandingkan kelainan EEG saat mulai pengobatan. Lebih dari 40\% kasus epilepsi tidak menunjukkan abnormalitas pada satu kali pemeriksaan EEG interiktal, berkurang menjadi 8\% jika dilakukan pemeriksaan serial dengan prosedur aktivasi yang sesuai terutama dengan deprivasi tidur. ${ }^{22,24}$

Identifikasi variabel yang memiliki pengaruh paling kuat sebagai faktor risiko respons awal OAE monoterapi adalah jumlah kejang $<10$ dan gambaran EEG normal pada penelitian ini. Etiologi tidak menjadi salah satu faktor risiko yang berhubungan dengan respons awal pengobatan. Pada penelitian ini etiologi epilepsi tidak bisa ditentukan secara pasti karena pemeriksaan genetik, metabolik, dan pencitraan yang canggih tidak dapat dilakukan. Dalam penelitian etiologi hanya ditentukan secara genetik dan struktural.

Namun, faktor jumlah kejang $<10$ dan gambaran EEG memiliki rentang indeks kepercayaan yang lebar. Hal ini dapat disebabkan adanya perbedaan karakteristik yang sangat besar antara kelompok respons awal yang baik dan yang buruk. Terdapat sel-sel dengan jumlah yang sangat rendah pada kedua variabel juga akan memperlebar rentang indeks kepercayaan. Penelitian lebih lanjut dengan jumlah subyek lebih besar dan waktu observasi tindak lanjut yang lebih lama dapat meningkatkan presisi prediksi risiko respons awal OAE monoterapi.

Anak epilepsi baru dengan etiologi genetik, status neurologi normal, bangkitan kejang umum, jumlah kejang < 10 dan gambaran EEG normal akan mencapai respons awal yang baik dalam 3 bulan pertama pengobatan. Jumlah kejang $\geq 10$ dan gambaran EEG yang abnormal merupakan faktor risiko respons awal 
yang buruk. Respons yang buruk adalah tidak adanya respons atau tidak tercapai kondisi bebas kejang dalam waktu 3 bulan berturut-turut selama pemberian OAE monoterapi sehingga memerlukan pemberian OAE kedua atau politerapi.

Jumlah kejang sebelum pengobatan dan gambaran EEG merupakan faktor yang berpengaruh terhadap respons awal pada penderita epilepsi baru.

\section{Kesimpulan}

Jumlah kejang dan gambaran EEG merupakan faktor risiko respons awal dalam 3 bulan pemberian OAE monoterapi.

\section{Daftar pustaka}

1. Kwan P, Brodie MJ. Early identification of refractory epilepsy. N Engl J Med 2000;342:314-9.

2. Dwi Putro W. Faktor risiko terjadinya epilepsi yang sukar disembuhkan pada anak dibawah umur 5 tahun: pengembangan sistem skoring untuk memprediksi secara dini (disertasi). Jakarta : Universitas Indonesia. Program Studi S3 Kedokteran,2012.

3. Geerts AT, Arts WFM, Brouwer OF, dkk. Validation of two prognostic models predicting outcome at two years after diagnosis in a new cohort of children with epilepsy: The dutch study of epilepsy in childhood. Epilepsia 2006;47: 960-5.

4. Geerts A, Arts WF, Stroink H, dkk. Course and outcome of childhood epilepsy: A 15-year follow-up of the Dutch Study of Epilepsy in Childhood. Epilepsia 2010;51:1189-97.

5. Arts WFM, Brouwer OF, Peters ACB, dkk. Course and prognosis of childhood epilepsy: 5-year follow-up of The Dutch study of epilepsy in childhood. Brain 2004;127:177484.

6. Scheffer IE. ILAE classification of the epilepsies:vposition paper of the ILAE commission for classification and terminologi. Epilepsia 2017;1:1-10.

7. Dragoumi P, Tzetzi O, Vargiami E, Pavlou E, Krikons K, Kontopoulos E. Clinical course and seizure outcome of idiopathic childhood epilepsy: determinants of early and longterm prognosis. BMC Neurology 2013;13:206-18.

8. Kwan P, Brodie MJ. Effectiveness of first antiepileptic drug. Epilepsia 2001;10: 2:1255-60.

9. McHugh JC, Delanty N. Epidemiology and classification of epilepsy: gender comparisons. Int Rev Neurobiol 2008;83:1125 .
10. Park KM dkk. Initial response to antiepileptic drugs in patients with newly diagnosed epilepsy. J Clin Neurosci 2014;21:923-6.

11. Casetta I, Granieri E, Monetti V, dkk. Early predictors of intractability in childhood epilepsy: a community-based case-control study in Copparo, Italy. Acta Neurol Scand 1999;99:329-33.

12. Wirrell E, Wong-Kisiel L, Mandrekor J. Nickels K. Predictor and course of medically intractable epilepsy in young children presenting before 36 month of age: A retrospective, population-based study. Epilepsia 2012;53:1563-9.

13. Mangunatmadja I. Prediksi luaran klinis pasien epilepsi fokal berusia kurang dari 3 tahun: Peran evolusi klinis dan elektroensefalografi serta magnetic resonance imaging. (disertasi). Jakarta: Fakultas Kedokteran Universitas Indonesia, Program Studi Doktor Ilmu Kedokteran, 2012.

14. Anon. Epilepsy fact sheet. World Health Organization media centre web page. Februari 2015. Diakses 1 oktober 2015. Didapat dari : http://www.who.int/mediacentrelfactsheets/ fs999/en/

15. Panayiotopoulos CP. Principles of therapy in the epilepsy. Dalam : A clinical guide to epileptic syndromes and their treatment. Edisi kedua. London: Springer Healthcare;2010.h.173-93.

16. Berg AT, Shinnar S, Levy SR, Testa FM, Smith-Rapaport S, Beckerman B. Early development of intractable epilepsy in children: a prospective study. Neurology. 2001;56:1445-52.

17. Camfield PA, Camfield CS, Gordon K, Dooley JJ. If a first antiepileptic drug fails to control a child's epilepsy, what are the chances of success with the new drug ? J Pediatr 1997;131:821-4.

18. Zhang Y, Yu N, Su L, Di Q. A prospective cohort study of prognosis for newly diagnosed epilepsy in east China. BMC Neurol 2013;13:1-8.

19. Mohanraj R, Brodie MJ. Diagnosing refractory epilepsy : response to sequential treatment schedules. Eur JNeurol.2006;13:277-82.

20. MacDonald BK, Johnson AL, Goodridge M, Cookerell OC, Sander JWAS, Shorvon SD. Factor predicting prognosis of epilepsy after presentation with seizures. Ann Neurol 2000;48:833-41.

21. Abimbola S, Martiniuk ALD, Hackett ML, Mohamed A, Anderson CS. Early predictor of remission in newly diagnosed epilepsy: a systemic approach to reviewing prognostic factor studies. Neurological Research. 2014;36:1-12.

22. Sillanpaa M, Schmidt D. Delayed time to first remission identifies poor long-term drug response of childhood-onset epilepsy:A prospective population-based study. Epilepsy Behavior 2009;16:507-11.

23. Ramzi, Soenarto Y, Hapsari S, Hakimi M. Prognostik factor of refractory epilepsy in children. Paediatr Indones 2008;48:269-72.

24. Panayiotopoulos CP. EEG and brain imaging. Dalam : A clinical guide to epileptic syndromes and their treatment. Edisi kedua. London : Springer Healthcare Ltd; 2010.h.147-69. 